\section{Rousing the sleeping genes}

David Weatherall

Altered Fates: Gene Therapy and the Re-tooling of Human Life. By Jeff Lyon and Peter Gorner. Norton: 1995. Pp. 636. \$27.50.

WHETHER or not gene therapy turns out to be "a medical revolution unparalleled in human history", as the jacket of Altered Fates predicts, few fields of medical research have received so much advance publicity during their gestation. Already two journals are devoted to it, several accounts of its history have been written and it features in numerous popular books on the potentials and dangers of the new genetics. And now the trials and tribulations of its early days, together with what it may hold in store for the future, are described in more than 600 pages of unreserved enthusiasm.

No one could deny that the field is busy. By the end of 1994, at least 100 clinical protocols involving gene transfer had been approved and it was estimated that the number of patients being treated, in the region of 300 , had doubled since 1993. But although, touch wood, this novel form of therapy seems to have been unexpectedly free of side effects, there is very limited evidence of its clinical efficacy: the symptoms of two children with an immunodeficiency syndrome resulting from adenine deaminase (ADA) deficiency appear to have been controlled successfully with repeated injections of lymphocytes into which normal ADA genes had been inserted; a patient with familial hypercholesterolaemia has shown a modest fall in blood cholesterol level after gene replacement; and a few cancer patients have responded to different forms of genetic manipulation.

Yet even here there are uncertainties. Despite the fact that the ADA and related replacement experiments have led to a successful patent application covering all ex vivo gene therapy in the United States, details of the work are still to be published. There are uncertainties about the interpretation of the results reported for the treatment of hypercholesterolaemia, and little is known about the outcome of the cancer patients.

So although it is a reasonable guess that gene therapy will have much to offer medical practice in the long term, a great deal more research is required, both into better ways of delivering genes to different cell populations and to ensure they work adequately in their new homes. What is more, it is still not clear whether some of the vectors used for gene transfer are absolutely safe.

Writing a popular book about research still in its infancy presents formidable problems. In particular, in trying to convey its excitement and potential it is tempting to play down the 'ifs' and 'buts', making it difficult to present a genuinely balanced account of the current state of the art. And if the authors are not scientists working close to the field and able to assess its literature, they must rely on the objectivity of the researchers that they interview. So what do two Pulitzer prizewinning journalists make of gene therapy after several years spent in the company of its practitioners?

The first half of Altered Fates is devoted mainly to the ADA story and French Anderson and his colleagues at the US National Institutes of Health (NIH) who began this research. After providing a particularly vivid pen-sketch of Anderson, the authors tell of his long struggle to obtain permission to carry out this experiment, the scepticism of his scientific colleagues about its feasibility or even whether it should have been attempted at all, and the personal lives of the young patients and their families. In the end, the authors come out strongly on the side of the NIH team, describing the ADA experiment as a "scientific milestone of incalculable magnitude". This may well be true, but surely now that this and related work on cancer at the NIH has led to a successful patent application, the details must be published so that the scientific community can judge for itself.

Parts of the second half of the book go over ground popularized elsewhere, particularly the discovery of the molecular pathology of single gene disorders such as Duchenne muscular dystrophy and cystic fibrosis. But it also explores the possibilities for their treatment by gene therapy and assesses the role of genetic manipulation for the management of some of the common disorders that plague Western societies such as heart disease, cancer and dementia. It finishes with a lively section on the application of genetic manipulation to the prolongation of life.

Although much of the book deals with areas of research that are now well established and in which the technology is based on the well-tried tools of molecular and cell biology, the final chapter, entitled "The Ultimate Frontier", moves into the uncharted new field of biogerontology. Here, we are told, gene therapy will be used to "rouse the sleeping genes in ageing people that once kept them young, lean, and muscular". No longer young and never having been lean or muscular, I read on at a pace usually reserved for the closing pages of a novel by P. D. James. Disappointingly however, it seems I am destined to remain geriatric and flabby for a while yet. Worse still, it is not always

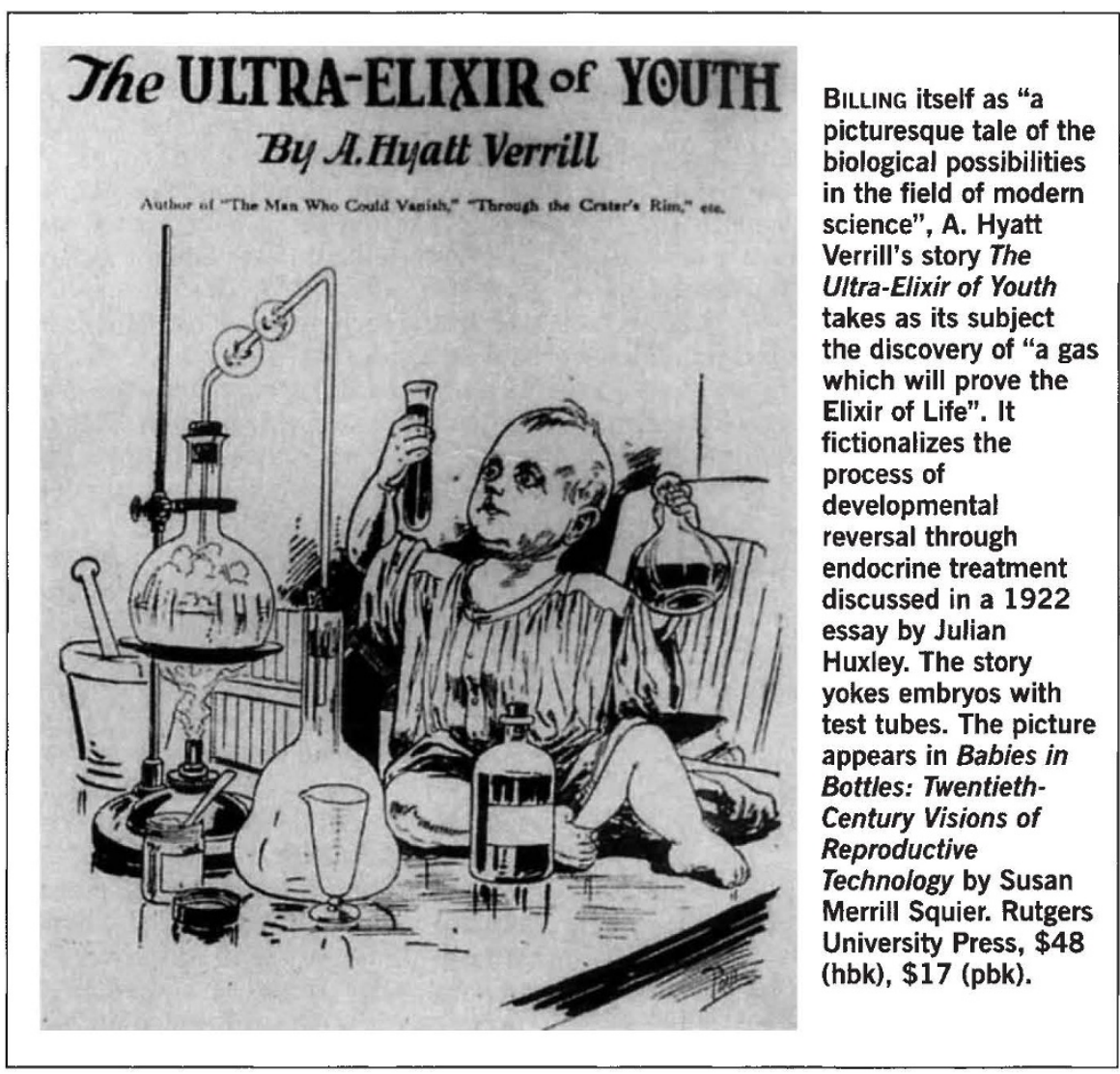


clear how some of the experiments in biogerontology described by the authors are related to human physiology, let alone to gene therapy. It may come as a surprise to endocrinologists, as it did to me when reading about the anti-cancer and antiageing properties of dehydroepiandrosterone (DHEA), to learn that "it is a build-up hormone that counters the teardown fight-or-flight hormone cortisone. . cortisone virtually pours from the thymus gland when mice are placed in wheel-like drums and spun round and round, but DHEA nullifies its effect". The scientist who is carrying out this work is quoted as saying: "the more you get into DHEA, the more it sounds like snake oil. . . it's working here, it's working there. Omigod!". (I was unsure about the derivation of the last word, but in this context it sounded appropriate enough when I read it aloud.)

Much of Altered Fates is couched in this way. Overall, it does not try to interpret the scientific complexities of gene therapy for a nonspecialist audience, but rather it highlights its considerable medical possibilities. Although it paints an extremely rosy picture and tends to play down many of the difficulties and disappointments that undoubtedly lie ahead, I suspect this is not the fault of the authors; clearly, much of what is said is taken directly from transcripts of the numerous interviews with the scientists they encountered during their background research. For this reason their story offers a fascinating commentary on the complex sociology of the gene-therapy field and, one suspects, of much of current research.

Nonspecialist readers who can live with this rather extravagant style of writing will learn a great deal about the background to gene therapy and gain some vivid insights into the way in which the biomedical sciences work, particularly in the United States. For the most part it is a lively piece of thoroughly researched journalism, which, although it says little about the underlying science, paints an enlightening picture of the lives, motivations and aspirations of today's researchers. Some readers may wonder if the larger-than-life characters depicted could possibly exist; from personal knowledge I can assure them that they do.

David Weatherall is at the Institute of Molecular Medicine, University of Oxford, John Radcliffe Hospital, Headington, Oxford OX3 9DU, UK.

\section{New in paperback \\ Concepts of Modern Mathematics by lan Stewart. Dover, $\$ 8.95$. A humorous and anecdotal introduction first published in 1975. \\ Ancient North America: The Archaeology of a Continent by Brian M. Fagan (2nd edn). Thames and Hudson, £16.95. An account for both general readers and students.}

\section{Going places}

Desmond King-Hele

A Travel Guide to Scientific Sites of the British Isles. By Charles Tanford and Jacqueline Reynolds. Wiley: 1995. Pp. 344. $£ 12.99$ (pbk).

SCIENCE, as much as literature, has a sense of place. Many scientific advances are linked with particular sites, and all scientists are born somewhere. In Britain the literary community has been far more successful in exploiting the benefits of local interest: Stratford makes much of William not always relevant or scientific, followed by chatty and useful travel hints, with opening hours and appropriate telephone numbers for museums, churches and so on. After the main guide come maps and indexes of names, places and subjects.

The first region is London, where we are offered a good selection of sites. But a much fuller guide is already available, in London Science by Dennis and Sylvia Rosen (Prion, 1994). Curiously enough, the memorials in Westminster Abbey and the blue plaques on London buildings are not listed in either book. Perhaps that would be too systematic and boring; but a reference to Alan

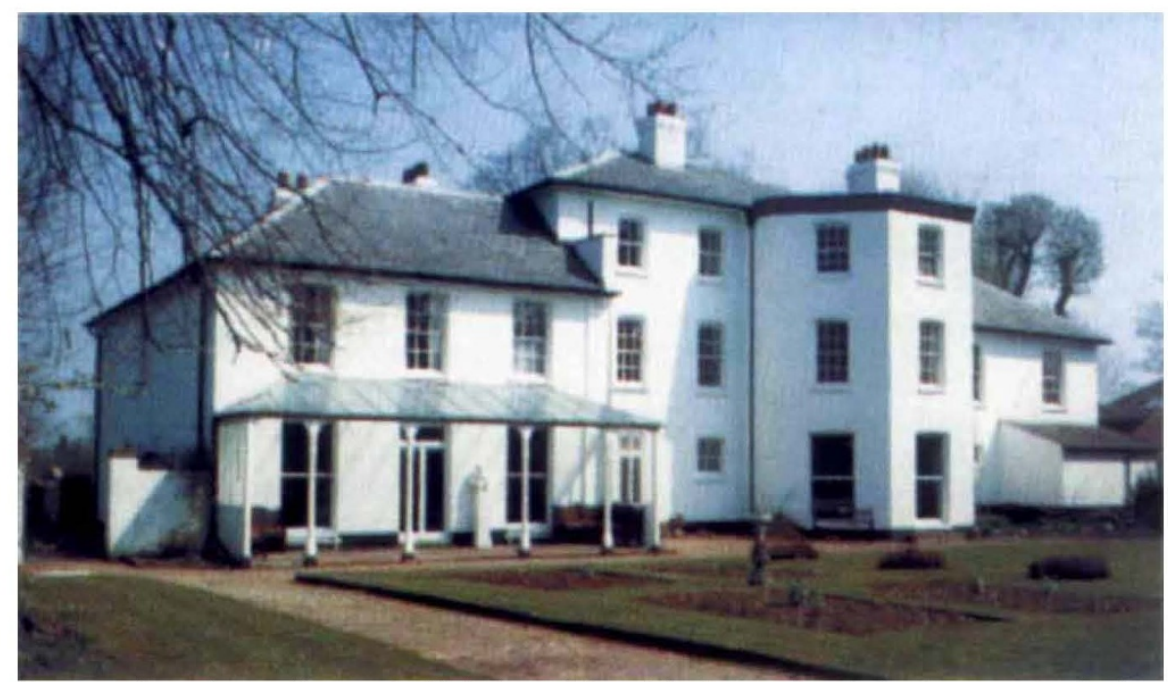

Home truths - Down House, the birthplace of Danwin's theory of evolution by natural selection.

Shakespeare; Shrewsbury makes little of Charles Darwin. There are many geographical guides to literary landmarks, few to sites with a scientific aroma.

So this new guide is much to be welcomed. The authors have visited most cities in the British Isles, and a wide spectrum of towns and villages, in pursuit of scientific anecdotes and ambience. Perhaps a famous or obscure scientist was born or worked there; perhaps the town's museum is of scientific interest. This procedure may seem rather hit-or-miss, but it makes for easier reading than a pedantically comprehensive listing.

The book begins with 48 pages about notable advances in science made in Britain, from Stonehenge to DNA. This lively sketch is refreshingly free of the fetters of political correctness that bind the chain-gang of academic historians, who may wince at some of the more simplistic judgements. The selection of topics is arguable, too, but the resulting concoction is pleasantly readable.

The main guide occupies the bulk of the book. The authors divide the British Isles into 11 regions, and within each the chosen towns are listed alphabetically. The entry for a typical town comprises a short essay or story, easy to read even if
Symons's Behind the Blue Plaques of London would be helpful.

After London we visit six regions of England - southeast, southwest and so on - then Wales, Scotland (mainland and island) and Ireland. The choice of towns, seemingly capricious, is wide enough to uncover a rich tapestry of littleknown facts and stories from the scientific past. We meet William of Occam, appropriately clean-shaven, in a stainedglass window at Ockham Church near Guildford. We admire the young curate Jeremiah Horrocks at Much Hoole near Preston as he observes the transit of Venus across the Sun in 1639, during intervals between the Sunday services. We are urged to make pilgrimages to the monuments of palaeoscience, the stone circles in the Orkney Islands and at Callanish near Stornoway. We are told of Benjamin Franklin pouring oil on the wavelets of Derwentwater; and of Manchester producing thousands of mourners at the funeral of John Dalton (an honour reserved today, it seems, for notorious criminals or politicians).

The book is a sitting target for petty criticism because it is so selective and often drifts away from science. Six Cambridge colleges are covered and the rest 